\title{
Dynamic response of buried silo caused by underground explosion
}

\author{
Sylwester Kobielak ${ }^{\mathrm{a}}$ and Theodor Krauthammer ${ }^{\mathrm{b}, *}$ \\ anstitute of Building Engineering, Wroclaw University of Technology 27 Wybrzeze Wyspianskiego, 50-370 \\ Wroclaw, Poland \\ ${ }^{\mathrm{b}}$ Protective Technology Center, Penn State University 3127 Research Drive, Cato Park, State College, PA 16801, \\ USA
}

Received 22 August 2003

Revised 16 March 2004

\begin{abstract}
Experimental results of normal and tangential pressures on a buried silo wall caused by buried charge explosions are presented in the paper. The measured pressures depended on the charge mass, and its burial depth and distance from the silo front. Pressures were measured by sensors attached to the silo wall at different depths along to four diametrically opposite line generators located at the front, rear and two sides. The influence of each parameter is analyzed and discussed.
\end{abstract}

\section{Introduction}

The subject of this work was studies of transient soil pressures acting on a protective cylindrical structure (silo) without a structural cover, buried surface flush, caused by underground explosions. This topic is not well understood, and it deserves further attention. During the last 20 years, emphasis has been placed on the dynamic response of box-type protective structures (Fig. 1). The upper edge of the roof slab of such a structures may be at the ground surface level, or covered by a thin layer of soil of thickness $\mathrm{h}$, in which $0<h<0.21$ [1], and $l$ is the clear span of the roof slab. Depending on the depth of burial, the following two burial conditions were suggested [1]:

- shallow-buried $0.21<\mathrm{h}<1.51$, and

- deeply buried, $h>1.51$.

It is essential to know the transient load transmitted through the soil from a detonation of a conventional buried charge to a shallow-buried structure, for which the load effects could be very critical, whereas, the same load is of much lower significance for deeper buried structures. One can define three basic buried charge positions, as shown in Fig. 1: above the structure, below the structure, and at its sides. Each of these positions represents a separate problem. Loads linked to explosions of a charge directed at the top of the structure have, so far, been satisfactorily determined both by analytical $[4,13-15,23]$ and experimental studies $[1,3]$. Despite considerable interest, there are, however, no exact theoretical methods to determine the distribution of dynamic pressures acting on a buried structure that result from buried explosions, placed below the structure or at its sides.

At present, the most widespread method of determining loads acting on the near and far side of a structure perpendicular to the direction of the blast is the semi-empirical solution proposed in [6], or its modified version in [23]. The formulas proposed in [6,23] were derived based on results obtained from a large test data base: first from World War II [16], between 1950 and 1985 at the Sandia National Laboratory, and at the US Army Waterways

\footnotetext{
*Corresponding author. Tel.: +1 814863 2932; Fax: +1 814865 9630; E-mail: tedk@psu.edu.
} 


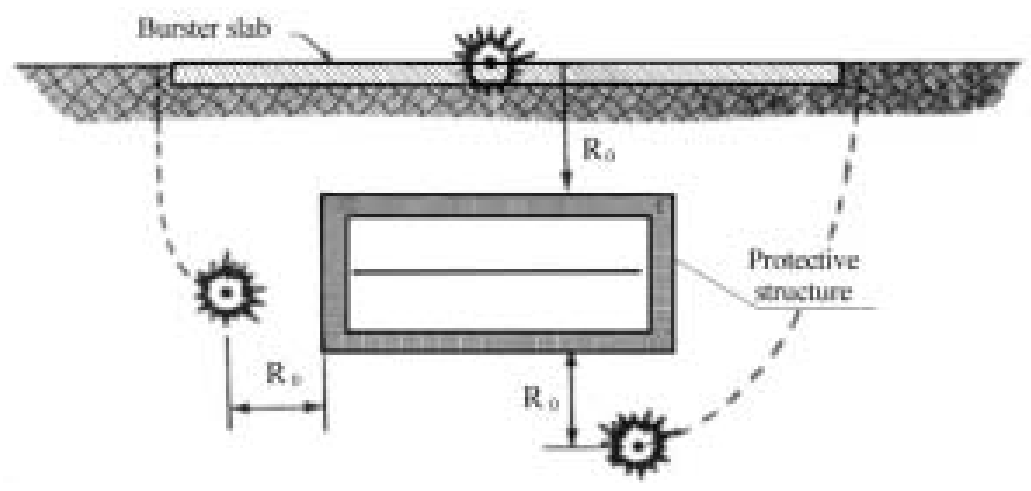

Fig. 1. Position of the explosion source with regard to a buried structure [23].

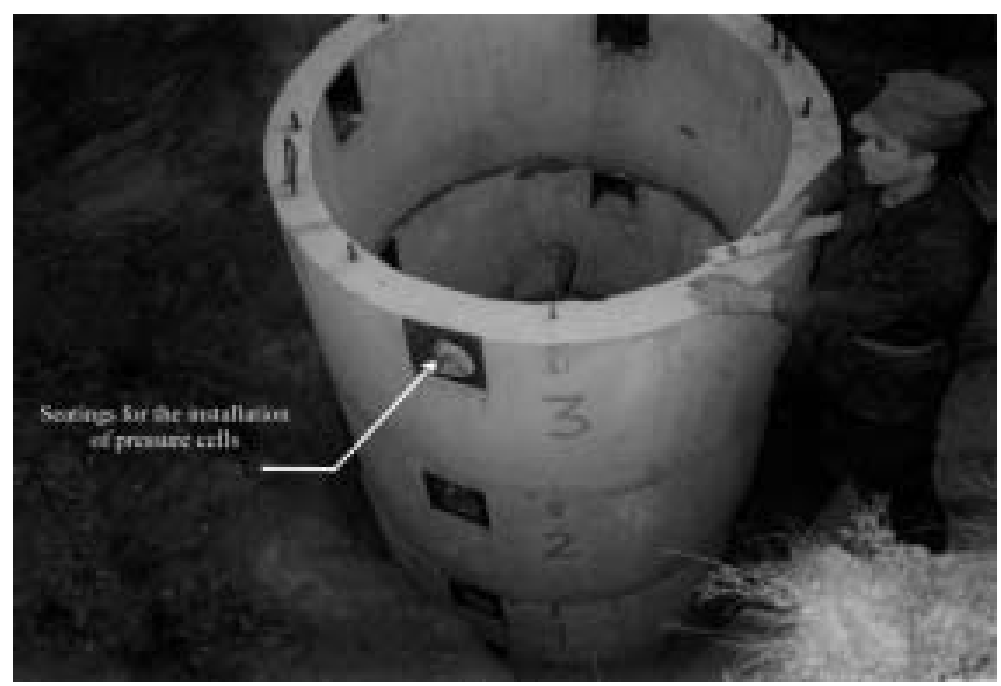

Fig. 2. Test silo assembly.

Experiment Station [16,20] and in the early 1980s at Southwest Research Institute [25]. However, these solutions are not suitable for determining of dynamic loads in the case of cylindrical structures with a circular plan as in the present silo tests. For such type of structures, one could try using the approximated solution in [22] that allows one to evaluate a constant value of dynamic pressure exerted on an upright, rigid, cylindrical vault, embedded in a uniform, viscoelastic stratum of constant thickness and infinite extent in the horizontal plane, subjected to seismic acceleration. There are empirical solutions for buried cylinders subjected to nuclear explosions, but not for buried cylinders subjected to buried conventional detonations (i.e., localized explosions vs. planar shock waves).

To alleviate this problem, a research team at the College of Military Engineering in Wrocław, Poland, initiated an experimental study program [10-12] addressing the dynamic soil pressure induced by buried explosions on buried structural fortifications. Tests were carried out to measure the normal and tangential soil pressures on a buried uncovered cylindrical structure (silo), induced by buried explosions.

\section{Test silo, devices, and equipment}

The test silo had an outside diameter $D=1.8 \mathrm{~m}$ and a height $H=3.40 \mathrm{~m}$, a wall thickness of $0.14 \mathrm{~m}$, and consisted of four reinforced concrete circular segments, each $0.85 \mathrm{~m}$. high (Fig. 2.). It was installed without a 


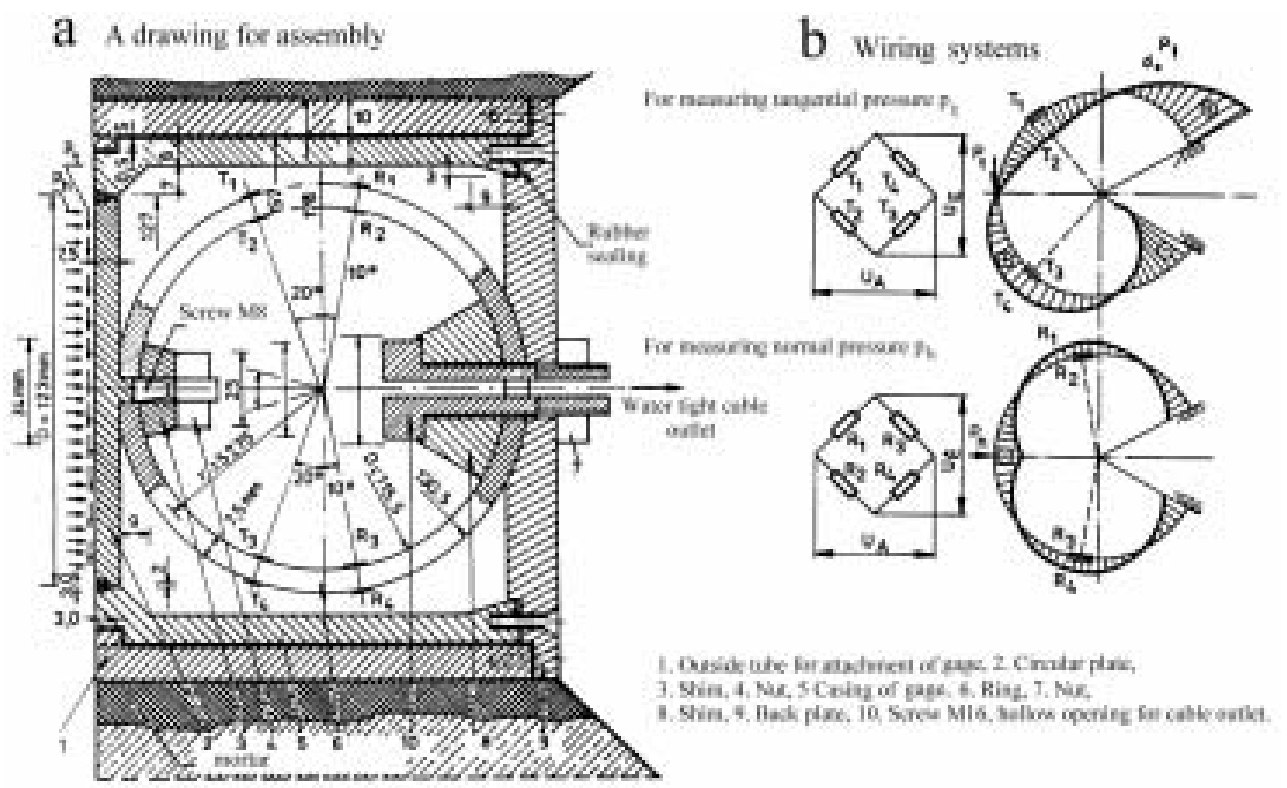

C view of measuring ring

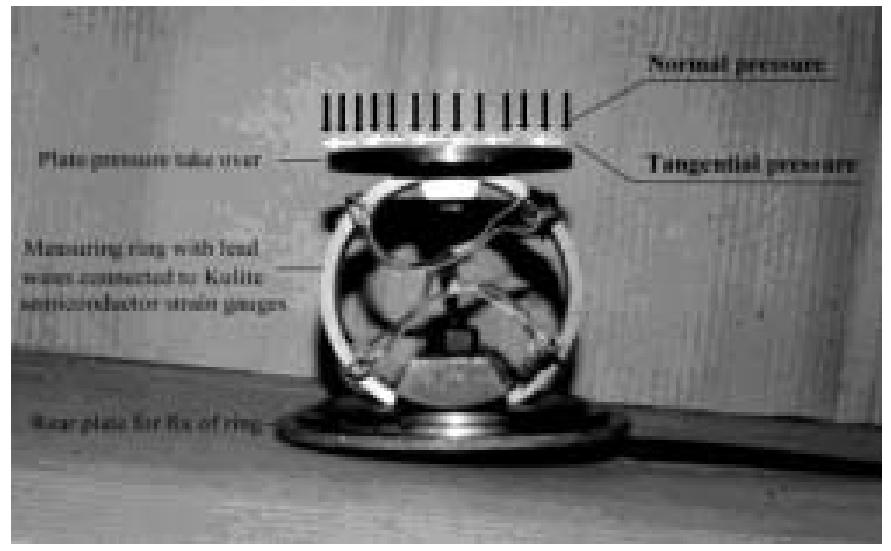

Fig. 3. Ring of gage for measuring the normal and tangential pressure component a. A drawing for assembly b. Wiring systems c. View of measuring ring.

structural cover in a previously prepared excavation, and the individual segments were connected by means of steel rods placed in holes that were filled with epoxy resin mortar.

The free space around the silo was backfilled with layers of soil, and compacted by manual vibrators to regain the in situ soil properties, whose estimated values were: size distribution of particular layers, bulk density, Poisson's ratio, natural water content and propagation velocity of longitudinal explosion wave.

To measure only the blast-induced pressure (static pressures were eliminated by zero adjustment), both its normal and tangential components were collected by ten ring dynamometer type pressure sensors (Fig. 3) equipped with Kulite semiconductor strain gauges. The pressure sensors operating on this principle were originally used by Novosad and Šmid [18]. Sensors were placed along the silo's four generators. Most of them (five) were installed at the front of the silo (their arrangement is provided in detail in Figs 10 and 11). Pressure gages were placed in holes (seatings) that were made in the concrete wall and attached to steel plates with screws (Fig. 2(a) shows a gage mounting by means of mortar, as originally planned). Only ten data locations were used due to the limited number of channels that could be recorded simultaneously. The data acquisition system consisted of a Racal Store Plus tape-recorder, 


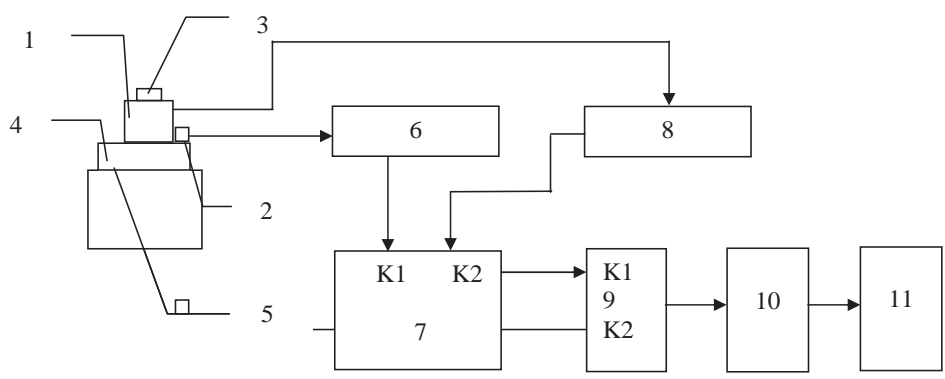

Fig. 4. Measuring set-up for dynamical calibration pressure gages: 1 - calibrated (tested) pressure gage, 2 - accelerometer type Bruel \& Kjaer 4268, 3-loading, 4 - gage securing device, 5 - vibration exciter (table) type STT-500, 6 - signal amplifier, type Bruel \& Kjaer 5001, 7 - RACAL Store Plus tape-recorder, 8-amplifier (bridge), 9 - data acquisition card iOtech DaqBook 200, 10-PC, 11 - printer.

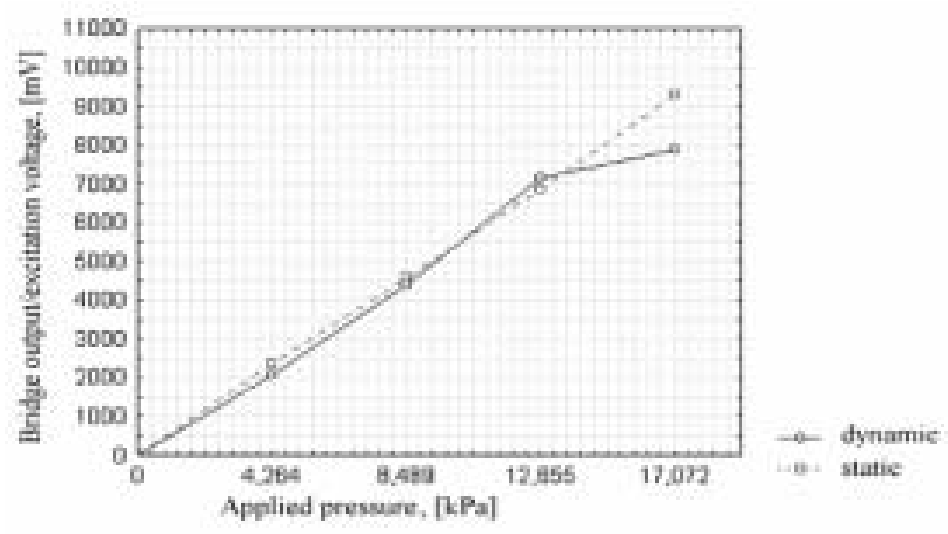

Fig. 5. Static and dynamic gage of normal pressure curves for acceleration of $5 \mathrm{~g}$.

an amplifier (bridge) for pressure sensors, an IOtech DaqBook 200 data acquisition card, a personal computer (PC), and a Gould Classic 6000 digital oscilloscope. The pressure sensors were calibrated both statically and dynamically. An electrodynamic vibration table (Fig. 4) proposed in [9] were used for the dynamic calibration of pressure cells for measuring the pressure caused by shock waves; other type are a peridulum and shock tube apparatuses [8].

The sensors were calibrated before each test, and Fig. 5 illustrates one of the dynamic calibration curves obtained. For comparison, the curve of static calibration is also given. These data show that gages read-outs in static and dynamic calibration ranges to $12.655 \mathrm{kPa}$ are close. The accelerometers were used with only factory calibration.

Besides the dynamic tests of gage responses to known applied transient loads, as described above, it was necessary that their natural frequency was from three to five times bigger than the largest frequency applied to the gages [21, 24]. An example of gage response and its spectral analysis result are shown in Fig. 6. The maximal vibration frequency of soil vs. distance from the charge to the front of the silo, obtained from frequency spectral analysis of soil pressure data measured on the structure at a on depth $0.95 \mathrm{~m}$ and recorded by gage No. 2, is shown in Fig. 7 . Spectral density distributions and their maximal values for other distances from the structure were similar. Therefore it was concluded that the applied gages meet the stated criteria for the transient event under consideration.

\section{Test program and its parameters}

A buried detonation is a chemical process whose outcome includes the release of a large amount of energy within a very short time and a confined space. This sudden energy release causes a variable, non-stationary movement of the soil around the charge that induces outward propagating shock waves in the soil. These shock waves interact with a buried structure in the layered soil (Fig. 8). The propagated explosion front presents an oblong shock wave 


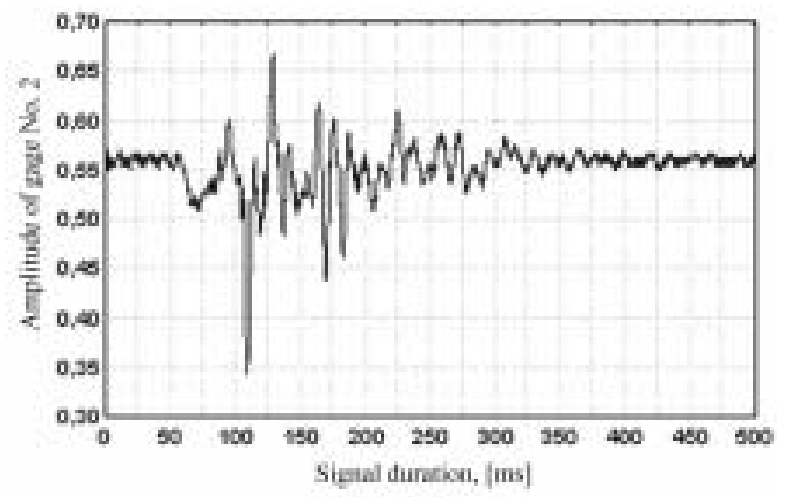

(a)

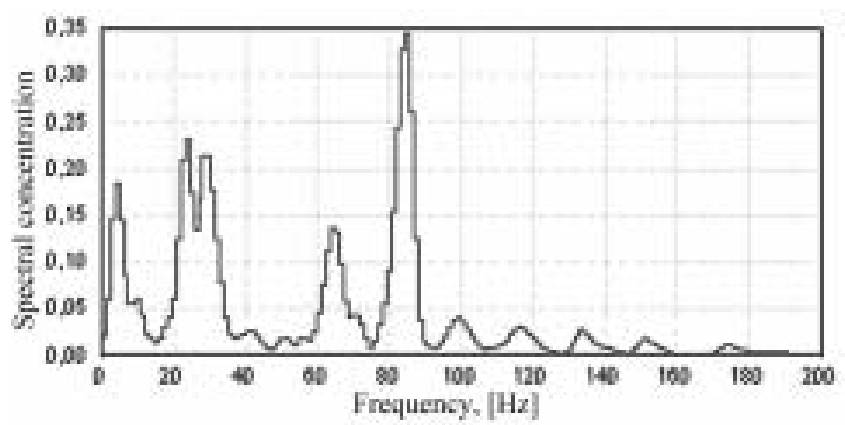

(b)

Fig. 6. (a) Dynamic characteristics of gage No. 2: gage response to impulse; (b) Dynamic characteristics of gage No. 2: spectral analysis of registered response.

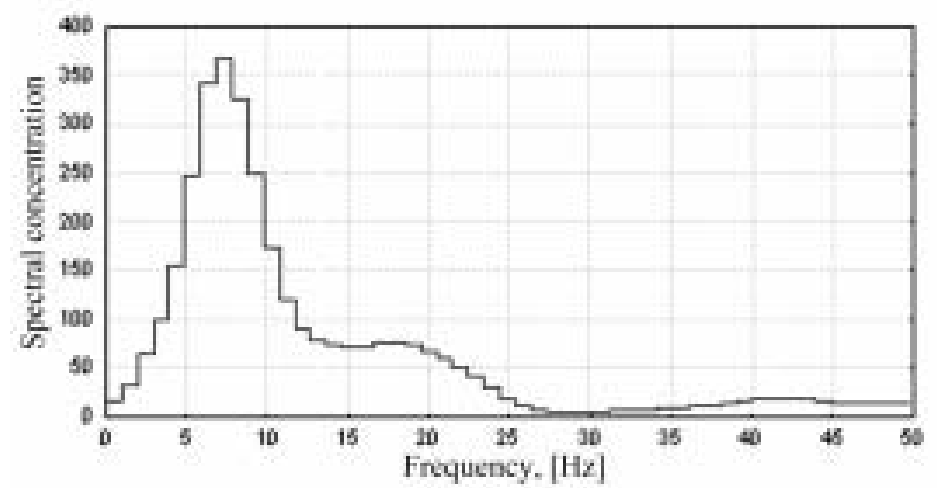

Fig. 7. Frequency spectral analysis of soil normal pressure registered by gage No. 2.

decaying with the distance $R$ away from the detonated charge. The explosion and its mechanical effects, such as pressure $p_{h}\left(\mathrm{kN} / \mathrm{m}^{2}\right)$ on the silo of a diameter $D$ and height $H(m)$, silo stiffness $E_{s} I_{s}$ and stress $\sigma_{h}\left(\mathrm{kN} / \mathrm{m}^{2}\right) \mathrm{may}$ be defined by the following parameters: the equivalent mass of the charge, $W_{T N T}(\mathrm{~kg})$, the mass of the silo structure, $W_{k}(\mathrm{~kg})$, the soil mass of the equivalent silo volume $W_{s}(\mathrm{~kg})$, its placement depth in soil, $h(\mathrm{~m})$.

The soil was characterized by the bulk density, $\rho_{d}$, and soil particle density, $\rho_{s}\left[\mathrm{~kg} / \mathrm{m}^{3}\right]$, Poisson's ratio, $\nu$, vibration frequency, $f$, propagation velocity of longitudinal explosion wave $c\left(\mathrm{~ms}^{-1}\right)$, the internal friction coefficient $\left(\tan \Phi_{u}\right)$, $\mu$, and the friction coefficient between the soil and the structure, $\mu_{1}$. The structure is embedded in three layered soil (Fig. 8). Particular type of soil layers were defined on the base of macroscopic tests as: 


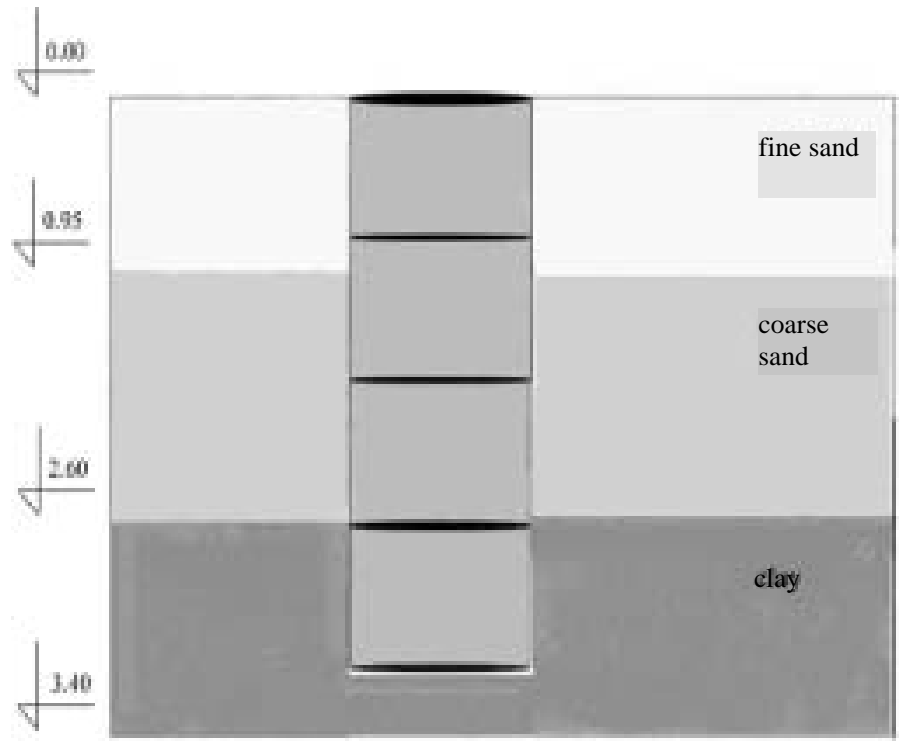

Fig. 8. Soil profile for test site.

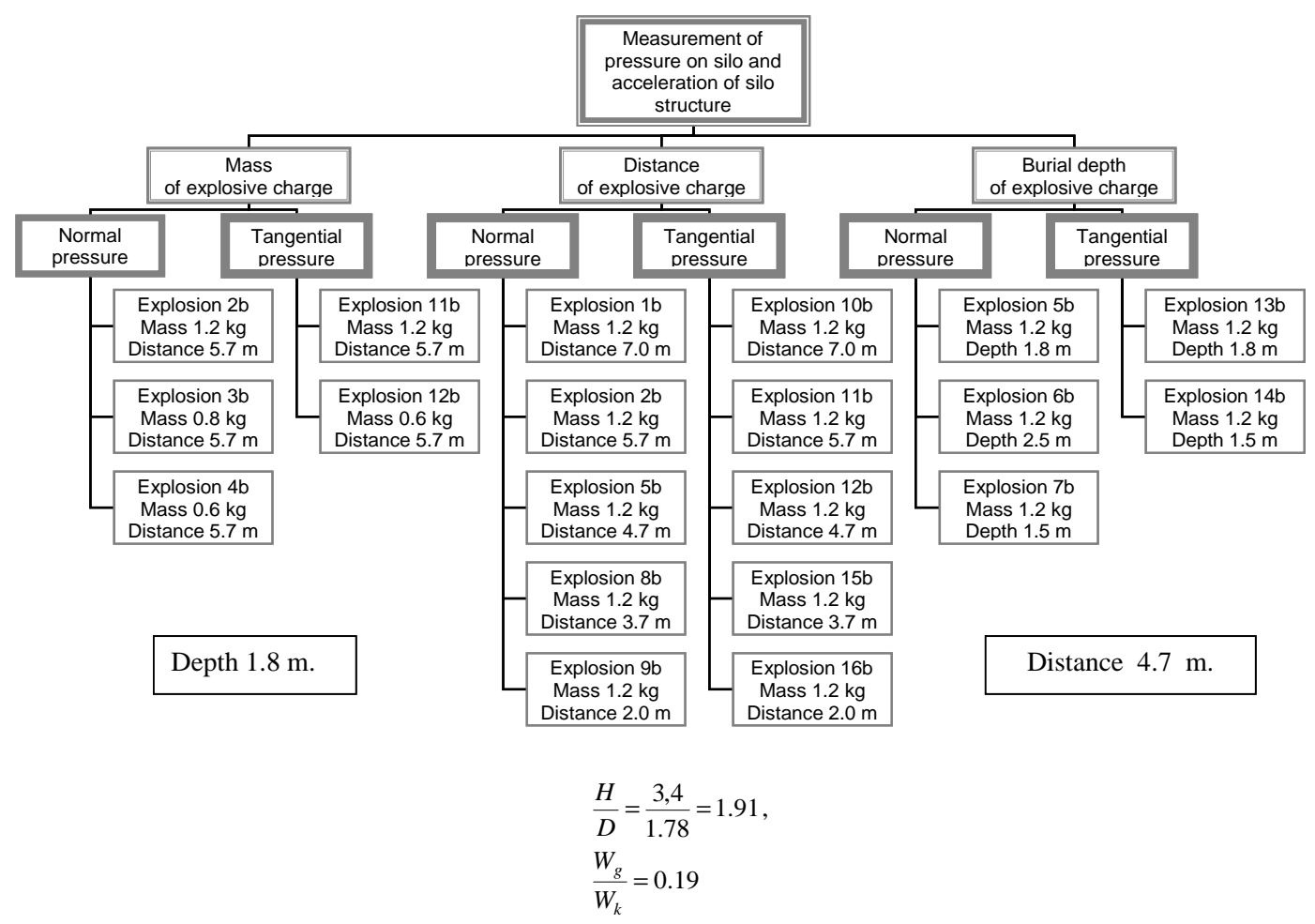

Fig. 9. Tests program.

1) medium sand with fraction contents in $\%$ :

$>2 \mathrm{~mm}-9 \%,>0.5 \mathrm{~mm}-39 \%,>0.25 \mathrm{~mm}-52 \%$,

2) fine sand with fraction contents in $\%$ :

$>2 \mathrm{~mm}-6 \%,>0.5 \mathrm{~mm}-46 \%,>0.25 \mathrm{~mm}-48 \%$, 


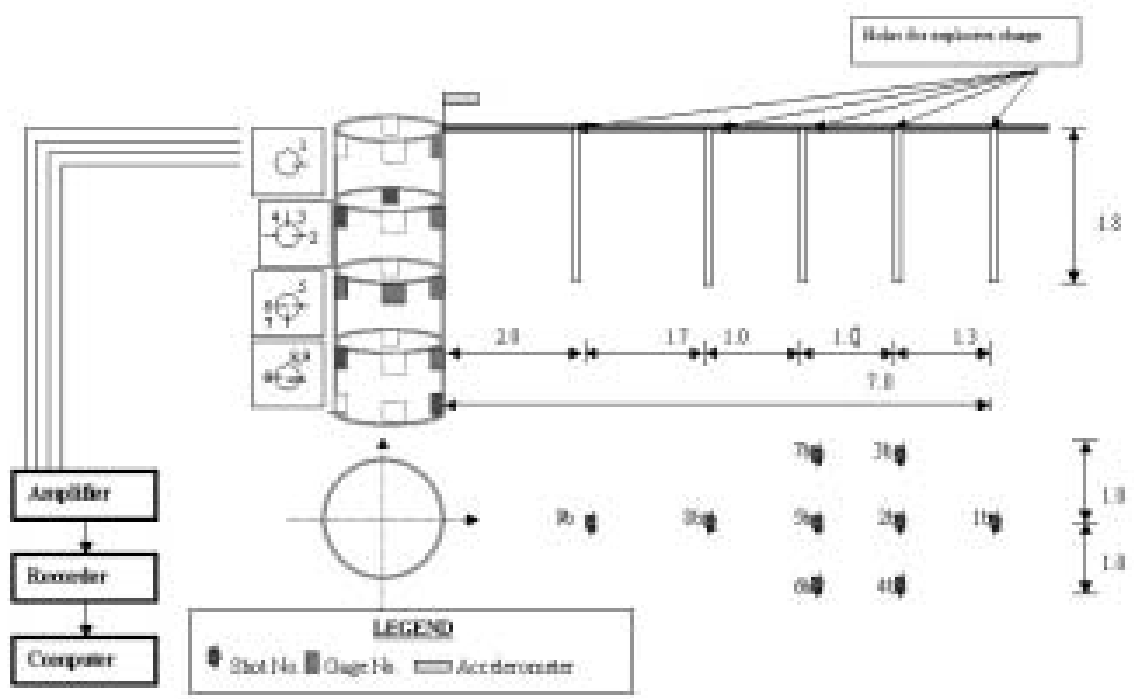

Fig. 10. Sequence of explosions and arrangement of gages measured normal pressure in the first stage of test.

Table 1

Soil properties in the site

\begin{tabular}{llcclcc}
\hline No. & Soil parameter & Symbol & Unit & $\begin{array}{l}\text { Medium } \\
\text { sand }\end{array}$ & Fine sand & Clay \\
\hline 1 & Particle density, & $\rho_{s}$ & $\mathrm{kgm}^{-3}$ & 2650 & 2654 & 2669 \\
2 & Bulk density, & $\rho_{d}$ & $\mathrm{kgm}^{-3}$ & 1652 & 1630 & 1764 \\
3 & Porosity $\left(1-\frac{\text { BulkDensity }}{\text { ParticleDensity }}\right) \cdot 100$ & $n$ & $\%$ & 37.7 & 38.6 & 33.9 \\
4 & Porosity index & $e$ & 1 & 0.604 & 0.628 & 0.513 \\
5 & Natural water content & $w_{n}$ & 1 & 14.1 & 13.2 & 17.0 \\
6 & Compaction degree, $I_{D}=\frac{e_{\max }-e}{e_{\max }-e_{\min }}$ & $I_{D}$ & 1 & 0.69 & 0.65 & - \\
& & & & compact. & medium & \\
& & & & & compact. & \\
7 & Plastic limit & $P L$ & 1 & - & - & 0.23 \\
8 & Plasticity index & $P I$ & 1 & - & - & 18 \\
9 & Poisson's ratio & $\nu$ & 1 & 0.25 & 0.30 & 0.25 \\
10 & Modulus elasticity, $E=2(1+\nu) G$ & $E$ & MPa & 134.44 & 84.03 & 39.27 \\
11 & Angle of internal friction & $\Phi_{u}$ & radian & 0.5760 & 0.5323 & 0.3456 \\
& & & degree & 33 & 30.5 & 19.8 \\
\hline
\end{tabular}

3) clay with fraction contents in $\%$ :

sand $-35 \%$, dust $-54 \%$, clay $-11 \%$.

Some of these soil properties occurring in the site were estimated and given in Table 1.

Assuming that soil behaviour is elastic, parameters another than given can be calculated from relationships given in paper [17].

Using the dimensional analysis method [2] leads to the following equation for the blast-induced pressure $p_{h}$ acting on the silo wall at a depth $z$ :

$$
p_{h}=\gamma_{s} D \Psi\left(\frac{R}{D}, \frac{H}{D}, \frac{h}{D}, \frac{z}{D}, \frac{c}{\sqrt{g D}}, \frac{W_{T N T}}{\gamma_{s} D^{3}}, \frac{W_{k}}{W_{s}}, \frac{E_{s} I_{s}}{\gamma_{s} D^{5}}, \frac{\gamma_{d}}{\gamma_{s}}, f, \mu, \mu_{1}, \nu\right)
$$

where, $\gamma_{s}=\rho_{s} g$, and $g$ is the acceleration of gravity. Bulk density $\rho_{d}$ is a measure of the mass of the dry soil per unit of volume. The soil particle density $\rho_{s}$ includes only the mass of the solid portion of the soil is its mass in a given volume after it has been compressed.

The pressure $p_{h}$ has been defined in Eq. (1) by means of thirteen dimensionless similarity parameters, where: 


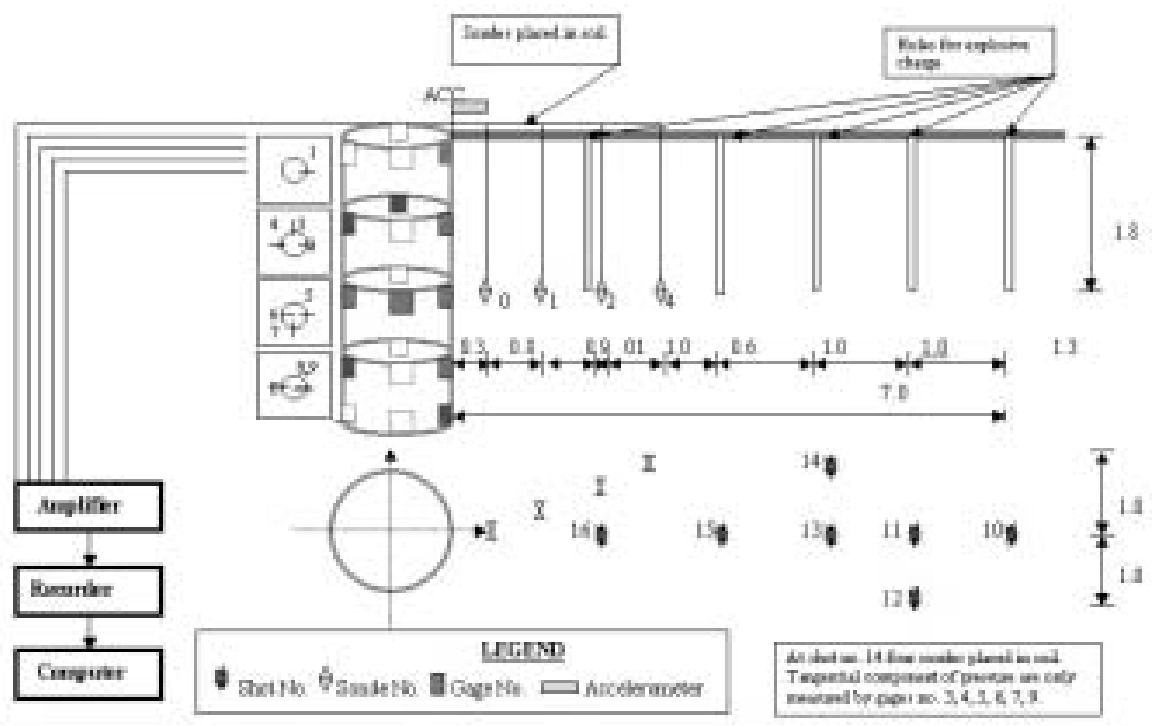

Fig. 11. Sequence of explosions and arrangement of gages measured tangential pressure in second stage of tests.

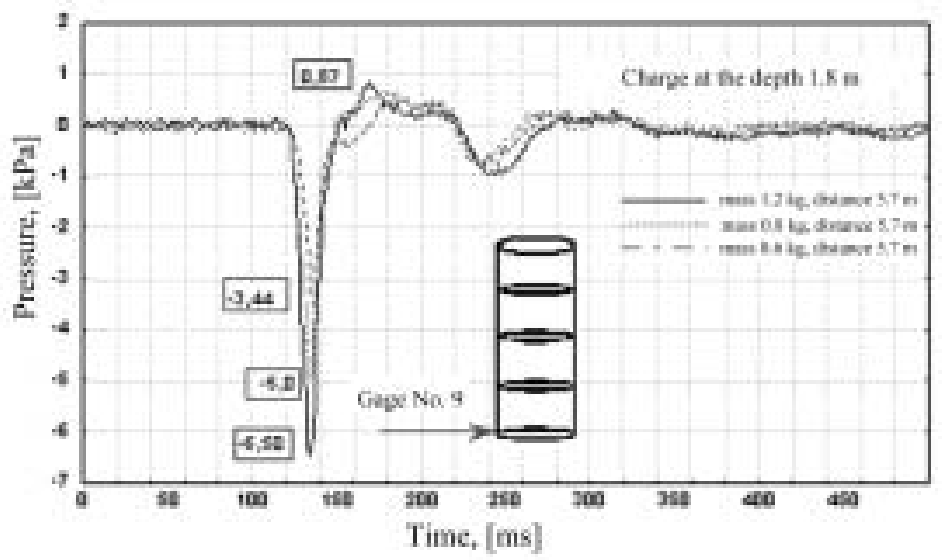

Fig. 12. Time histories of normal pressure depending on the charge mass recorded by gage No. 9 (front).

$$
\pi_{1}=R / D, \pi_{2}=H / D, \pi_{3}=h / D, \ldots, \pi_{13}=\nu
$$

The pressure magnitude on any silo with diameter of $D_{0}$ can be determined from the following equation:

$$
p_{h_{o}}=\gamma_{s} D_{o} \psi\left(\pi_{1}, \pi_{2}, \pi_{3}, \ldots, \pi_{13}\right)
$$

where: $\psi\left(\pi_{1}, \pi_{2}, \pi_{3}, \ldots, \pi_{13}\right)=\frac{p_{h m}}{\gamma_{s} D_{m}}$ is the dimensionless pressure coefficient to be determined from test data for a cylindrical structure of diameter $D_{m}$, that satisfies all $\pi_{i}$ parameters for model $(m)$ and object $(o)$, i.e. $\pi_{i m}=\pi_{i o}$, by simultaneous assumption of a soil profile (Fig. 8).

The test program is illustrated in Fig. 9. The tests were divided into two stages: In the first stage the normal soil pressure exerted on the structure were recorded by ten pressure sensors installed in the silo wall. The influence of the charge mass and its depth on the normal pressure (n. p.) acting on the silo wall was studied, as follows: the effects of the charge mass was studied in tests $2 b, 3 b$, and $4 b$; the influence of charge distance was studied in the tests $1 b, 2 b, 5 b, 8 b$ and $9 b$; and the influence of the charge depth was studied in tests $5 b, 6 b$, and $7 b$. The other tests were used to determine the effect of distance on the pressure. 


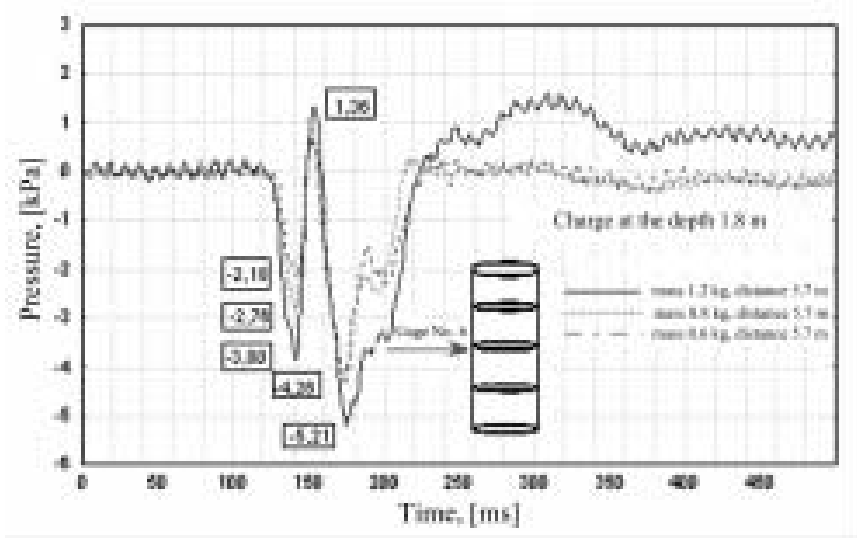

Fig. 13. Time histories of normal pressure depending on the charge mass recorded by gage No. 6 (rear).

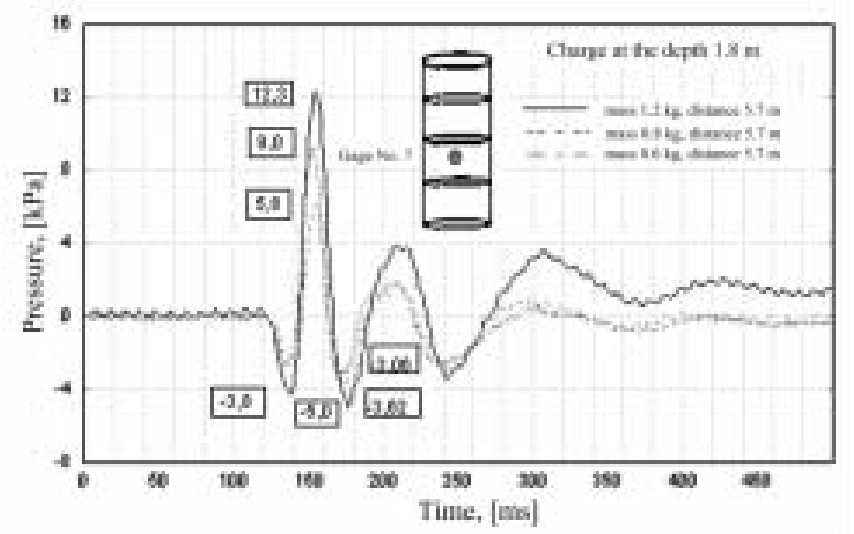

Fig. 14. Time histories of normal pressure depending on the charge mass recorded by gage No. 7 (side).

In the second stage, using the same types of test, the tangential pressure (t. p.) component acting on the structure, and stresses within the soil (not presented here) were studied with stress gages. Here, the influence of the same parameters, as in the first stage (i.e., charge mass, distance, and depth) on the tangential pressure (t. p.) was studied in tests: 10b, 11b, 12b, 13b and 14b, 15b, 16b. Figures 10 and 11 describe the arrangement of pressure gages, stress gages, accelerometers, the distribution of charges, and the sequence of their explosions.

In this paper, the tests results are summarized for three charge parameters namely: mass ( 3 values for n. p. and 2 values for $\mathrm{t}$. p.), distance ( 5 values for n. p. and 5 values for t. p.), and depth ( 3 values for n. p. and 2 values for $t$. p.). Also measured was the acceleration at one point on the silo structure. A total of 176 data records were acquired, as follows: In the first stage for 9 shots $\times(10$ pressures gages + one acceleration sensor $)=99$ records (see Fig. 10), and in the second stage for 7 shots $\times(10$ pressure gages + one acceleration sensor $)=77$ records (see Fig. 11).

\section{Test results}

\subsection{Charge mass effects on normal pressure}

The mass of the explosive charge $W_{T N T}$ was varied to explore how it influenced the magnitude of the normal and tangential components of soil pressure affecting the structure. Charges consisted of $1.2 \mathrm{~kg}, 0.8 \mathrm{~kg}$, and $0.6 \mathrm{~kg}$ of TNT. The charge to-silo-direction was alternated so that similar soil conditions were maintained during each detonation. It can be expected that different shot-to-structure directions, relative to the axes of placed pressure cells, 


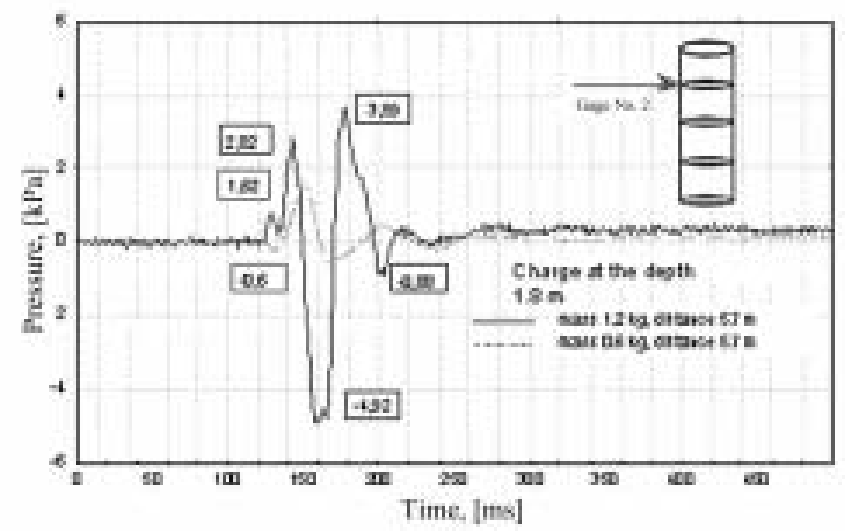

Fig. 15. Time histories of tangential pressure depending on the charge mass recorded by gage No. 2 (front).

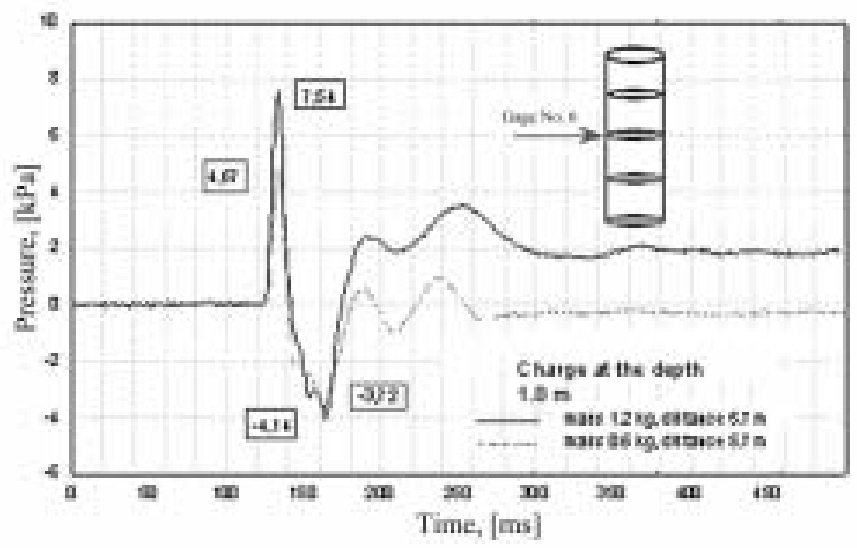

Fig. 16. Time histories of tangential pressure depending on the charge mass recorded by gage No. 6 (rear).

will caused some changes in the soil pressure distribution on the silo wall. The charges were placed at a depth of $1.8 \mathrm{~m}$, and detonated at a distance of $5.7 \mathrm{~m}$ from the front of the structure. The measurement surfaces of the pressure sensors were placed flush with the surface. The arrows in Figs 12, 13, 15, 16, 17, 18 and 20 indicate the location on the silo where the sensors were placed, as well as the propagation direction of the shock waves.

Pressure sensors distributed along four diametrically-opposite generator lines, i.e., the front, rear and the two sides, measured the normal and tangential pressure exerted on the silo wall. Figures 12, 13, and 14 present examples of normal pressures-time histories recorded by gages $\operatorname{Nos} 9,6$, and 7, respectively. The influence of the charge mass on the normal pressure value is clearly visible on these data.

The highest indications of normal pressure at the front surface were obtained by gage No. 9 (Fig. 12), placed at the bottom of the silo, whereas, gage No. 6 (Fig. 13) recorded the maximum pressure on the rear surface. The value of the pressure on the silo rear wall is much higher than the pressure at the same level recorded by gage No. 5, placed on the front surface of the silo. Differences were also noted in the type of the pressure-time histories, on the front and rear surfaces.

In turn, the pressure-time history acting the sides of the silo, recorded by gage No. 7, is presented in Fig. 14 . Comparing these data with those for the pressure acting on the rear and front surfaces of the structure, one can clearly see the appearance of a large maximally opposite pressure noted by a change in sign (positive, instead of negative).

The pressures in Figs 13 and 14 shows that the gage measurements did not return to zero after the shock wave passed, indicating a base drift. This was caused by the inelastic soil behavior, associated with permanent deformations due to the passage of the shock wave. Such behavior was also observed in [7] during an earthquake. It should be 


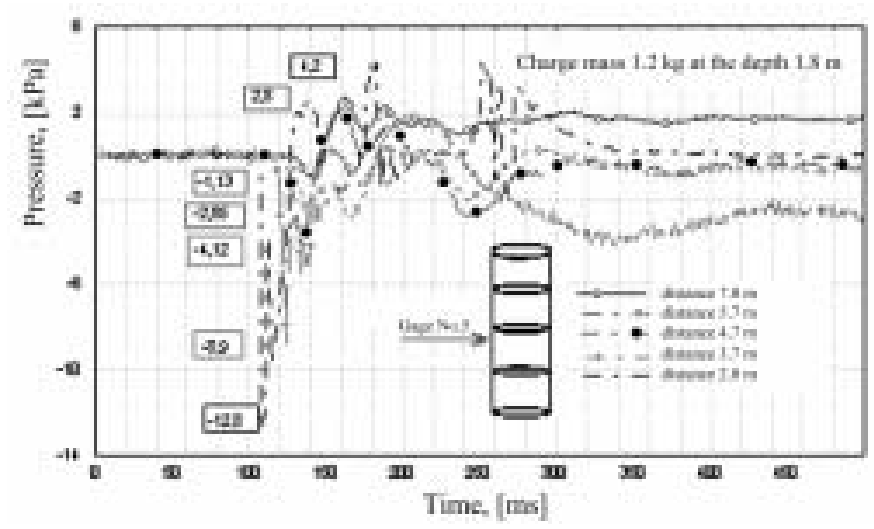

Fig. 17. Time histories of normal pressure depending on the distance of the charge-silo, recorded by gage No. 5 (front).

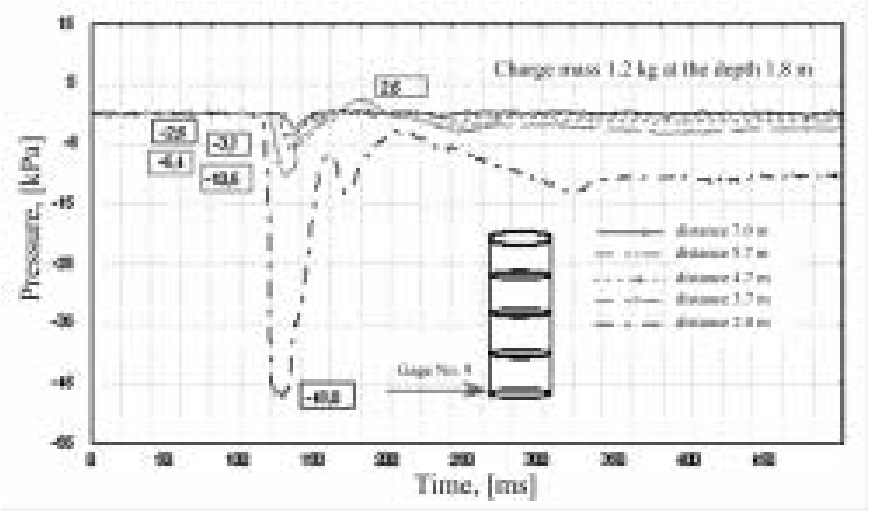

Fig. 18. Time histories of normal pressure depending on the distance of the charge-silo, recorded by gage No. 9 (front).

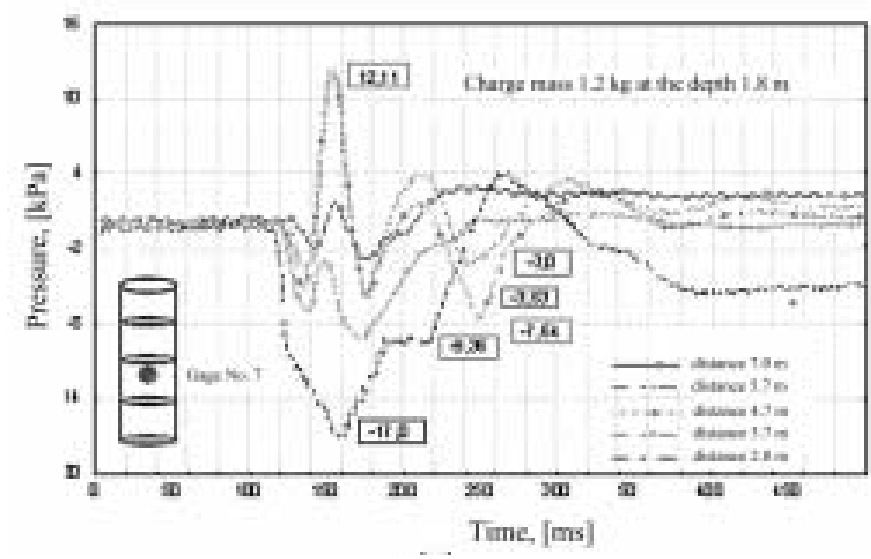

Fig. 19. Time Histories of normal pressure depending on the distance of the charge-silo, recorded by gage No. 7 (side).

emphasized that the maximum pressure value for the same distance of the detonation charge and the depth of burial vary with the time after the detonations. 


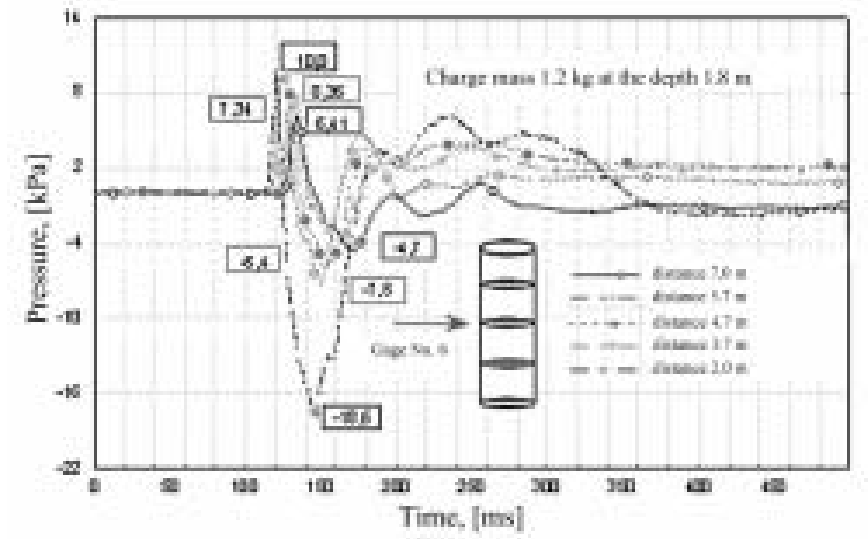

Fig. 20. Time Histories of tangential pressure depending on the distance of the charge-silo, recorded by gage No. 6 (rear).

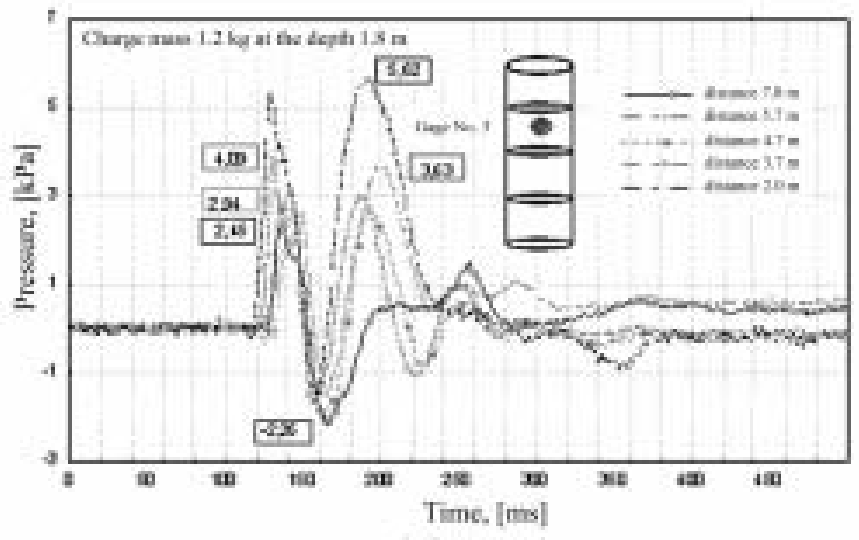

Fig. 21. Time Histories of tangential pressure depending on the distance of the charge-cylindrical structure, recorded by gage No. 3 (side).

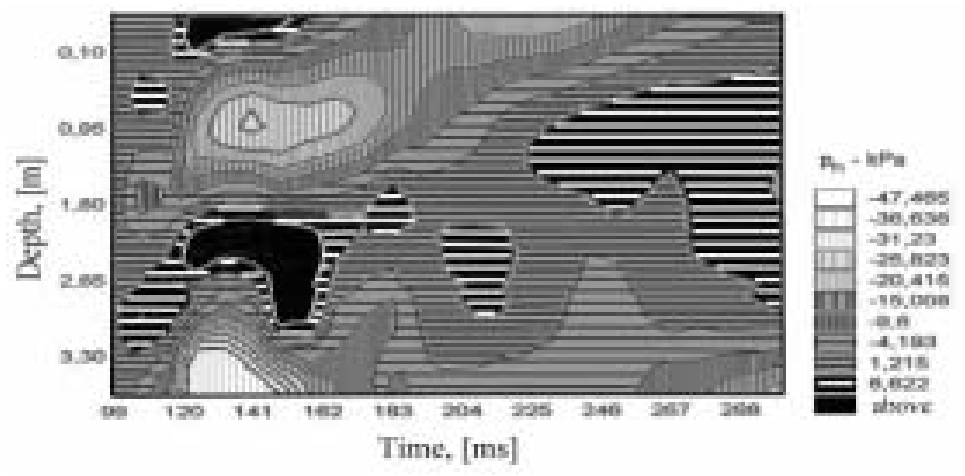

Fig. 22. Contour distribution of normal pressure $p_{h}$ along line generator 1 (front of cylinder) caused by an explosion of a $1.2 \mathrm{~kg}$ charge from distance of a $2.0 \mathrm{~m}$.

\subsection{Charge mass effect on tangential pressure}

The time-history of the tangential pressure component on front and rear silo surfaces are depicted in Figs 15 and 16, respectively. The maximum pressure value acting on the front surface was found at the bottom of the structure, 


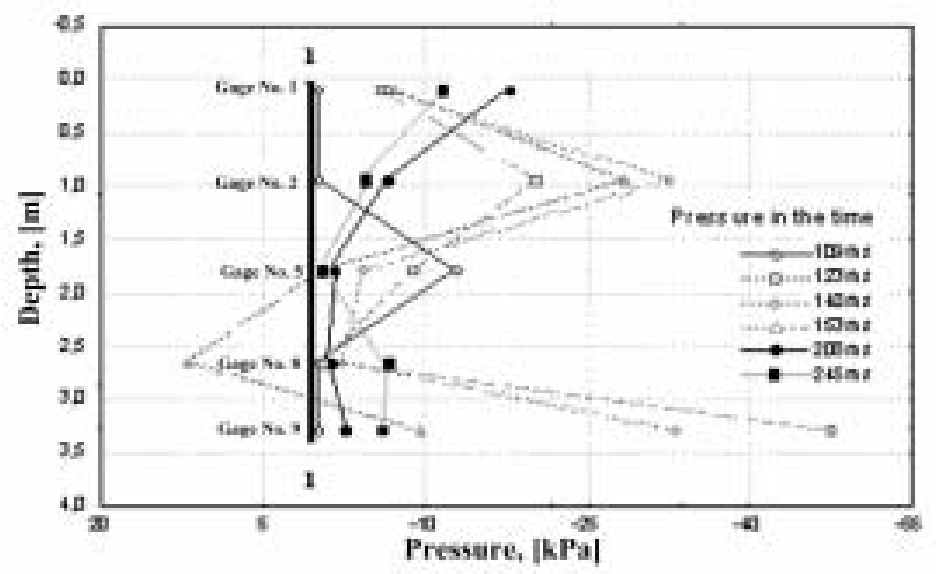

Fig. 23. Distribution of normal pressure along line generator 1 during the explosion of a $1.2 \mathrm{~kg}$ charge from distance of 2.0 meters.

Table 2

Values of ground shock coupling coefficient $f[1]$

\begin{tabular}{lcccccccc}
\hline Scaled depth $\mathrm{h} / \mathrm{W}^{1 / 3}$ in $\mathrm{ft} / \mathrm{lb}^{1 / 3}$ & 0.0 & 0.2 & 0.4 & 0.6 & 0.8 & 1.0 & 1.2 & 1.4 \\
\hline Coupling factor $f$ & 0.4 & 0.6 & 0.7 & 0.8 & 0.88 & 0.92 & 0.97 & 1.0 \\
\hline
\end{tabular}

just as it was in the normal pressure but almost at the top (gage No. 2, Fig. 15). As for the normal pressure, the maximum tangential pressure was not measured on the front but on the rear surface (Fig. 16).

\subsection{Charge distance effect on normal and tangential pressures}

In these tests, $1.2 \mathrm{~kg}$ TNT charges were placed at distances between $7.0 \mathrm{~m}$ and $2.0 \mathrm{~m}$ from the silo and at a depth of $1.8 \mathrm{~m}$. To maintain similar conditions during particular detonations, the measurements of normal and tangential pressures were carried out separately, by changing the direction of the detonation source with respect to the silo. The time-histories for normal and tangential pressure recorded by pressure gages installed on the front, rear and side surfaces, depending on the charge to structure distance, are shown Figs 17-21. They indicate clearly how the distance of the placed charge influenced the magnitude of the normal and tangential pressures.

All distributions of tangential pressure along the height have varied sign in time. Maximal tangential pressure along line 1-1 occurred at $175 \mathrm{~ms}$ at the level of gage no. 8 (not presented here), and was equal $+15.7 \mathrm{kPa}$ (upwards). But general maximal values were registered by gages placed on rear surface. Namely, gage no. 4 indicated at $125 \mathrm{~ms}$ a pressure of $+18.7 \mathrm{kPa}$, while gage no. 6 indicated at $150 \mathrm{~ms}$ a pressure of opposite sign of $-18.6 \mathrm{kPa}$ (see Fig. 20).

\section{Analysis of test results}

The comparison of particular distributions of the maximum normal pressure acting on the silo front surface indicated that its value increased as the distance between the structure and the detonation source decreased. The maximum normal pressure at the shortest distance from the buried charge to the structure (distance 2.0 meters) was recorded at the bottom of the silo (Figs 22, 23). The distribution of the normal pressure varied, depending on the time after the explosion (Figs 22, 23). The earliest maximum normal pressure (already at $109 \mathrm{~ms}$ ) was recorded by gage No. 5, placed at the same level as the detonated charge.

Surface "matching" of pressure distribution on the silo wall was obtained by a least squares fit with a two variables $\mathrm{k}$-th degree polynomial for the test data (a limited number of measurement points was available) that resulted in the continuous contours shown in Fig. 22. The maximal pressure occurred near the structure bottom at early time (Fig. 23). Maximal pressure of the decaying wave was registered by gage no. 1 at the silo top at $245 \mathrm{~ms}$. The 


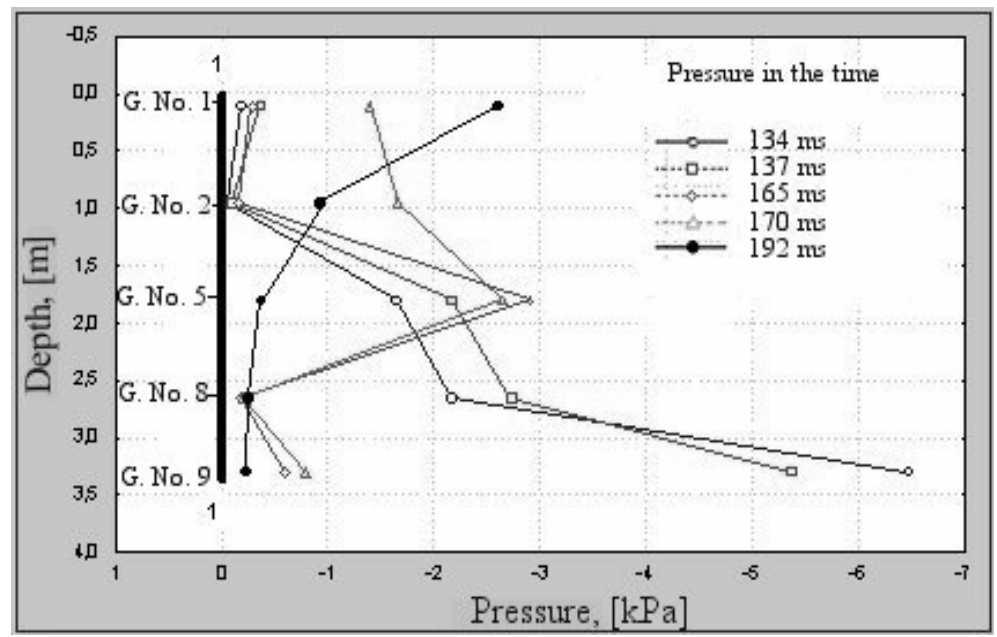

Fig. 24. Distribution of normal pressure $p_{h}$ in the time along line generator 1 during explosion of a $1.2 \mathrm{~kg}$ from distance of $5.7 \mathrm{~m}$, placed at the depth $1.8 \mathrm{~m}$.

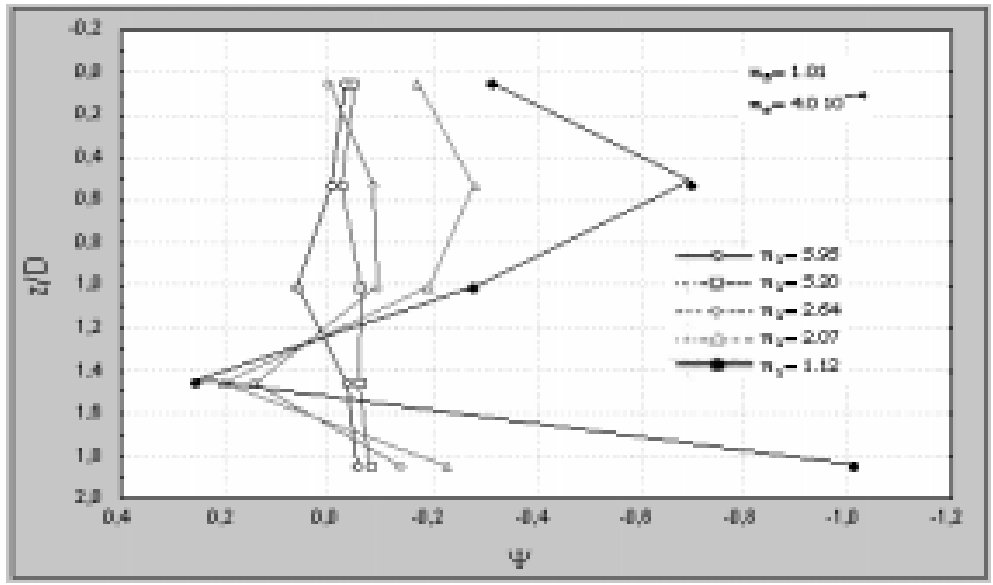

Fig. 25. Influence of distance parameter $\pi_{1}$ on value of normal pressure coefficient $\Psi$.

appearance of maximal value of pressure at the bottom might have been caused by underlying clay which typical to this site. The top soil layers were coarse and fine sand (Fig. 8) that were backfilled after structure was placed. For the largest distance of $5.7 \mathrm{~m}$, the pressure distribution was different (Fig. 24). The recorded maximal normal pressures appeared first at the bottom of the structure, and then moved over time upwards to reach the upper part of the of pressure distribution on the silo wall.

Besides the charge mass, its distance and depth parameters have a decisive influence on the normal and tangential pressures acting on silo wall. The influence of $\pi_{1}=R / D$ on $\Psi=p_{h} / \rho \cdot D$ is shown in Fig. 25. Three types of distribution curves are noted for the following distances of detonation: large $\left(R=7.0 \mathrm{~m} \rightarrow \pi_{1}=3.93\right.$ and $\left.R=5.7 \mathrm{~m} \rightarrow \pi_{1}=3.20\right)$; medium $\left(R=4.7 \mathrm{~m} \rightarrow \pi_{1}=2.64\right)$, and small $\left(R=3.7 \mathrm{~m} \rightarrow \pi_{1}=2.07\right.$ and $R=2.0 \mathrm{~m}$ $\left.\rightarrow \pi_{1}=1.12\right)$. At each shot distance, with the exception of $R=4.7 \mathrm{~m}\left(\pi_{1}=2.64\right)$, the maximal pressure appeared at the bottom of structure. It was noted with interest that gage no. 8 exhibited a considerable pressure decreases for a small charge-to-structure detonation distance.

The normal pressure values (coefficients) in dimensionless form (Fig. 26) depend on the charge depth parameter $\pi_{3}$ that shows clearly the influence of charge depth on the value of the coefficient $\Psi$. The value of this coefficient increased with the increase of the depth parameter $\pi_{3}$. A maximal value of $\Psi$ was reached when the depth parameter was equal to $\pi_{4}=1.0$, i.e., at the depth of gage no. $8(1.8 \mathrm{~m})$. A quite different trend of the dependence of $\Psi$ on the 


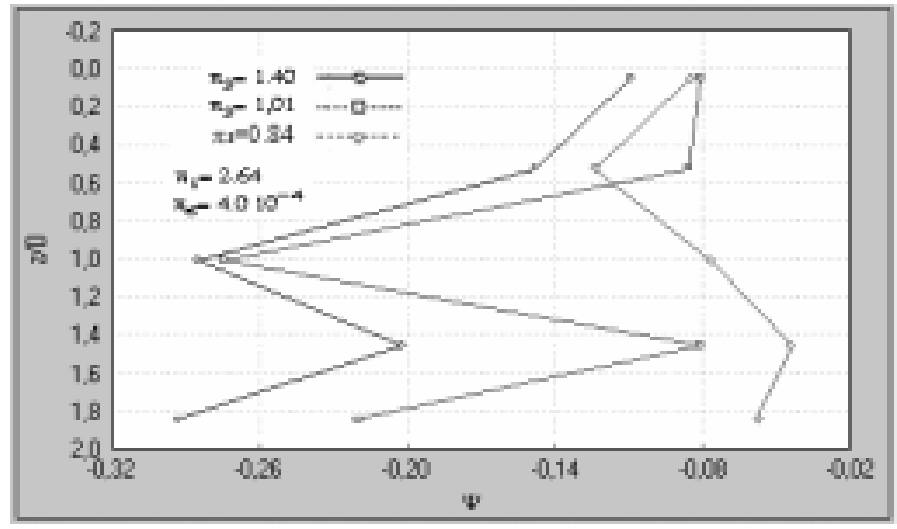

Fig. 26. Influence of depth charge parameter $\pi_{3}$ on value normal pressure coefficient $\Psi$.

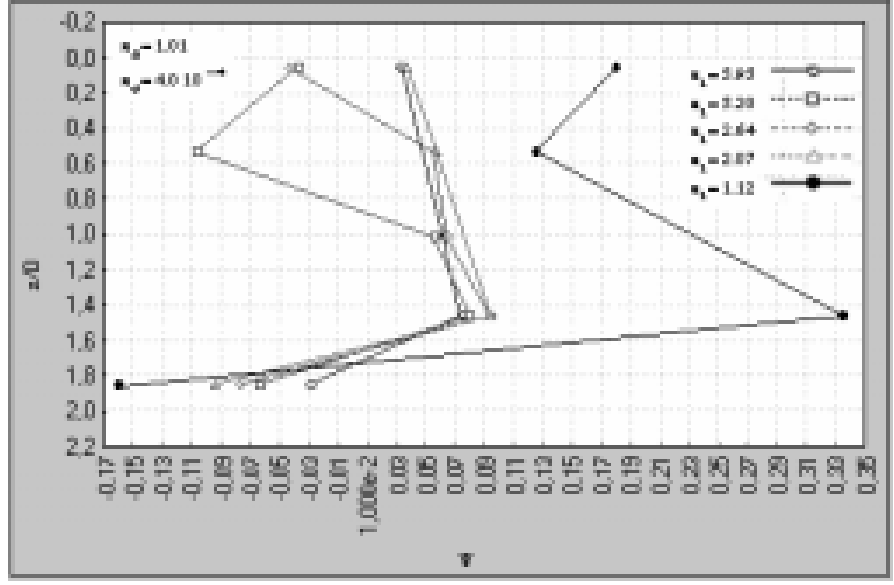

Fig. 27. Influence of charge distance parameter $\pi_{1}$ on value of tangential pressure coefficient $\Psi$.

parameter $\pi_{4}$ was noted during a charge explosion at the depth of $1.5 \mathrm{~m}\left(\pi_{3}=0.84\right)$, because this depth was close to optimum depth, where venting (surface spall) had not occurred yet. Therefore, the pressure for this parameter value was relatively small.

Figures 27 and 28 show the influence of the parameters of the distance $\pi_{1}$, and the depth $\pi_{3}$ on the value of the tangential pressure coefficient $\Psi$, respectively. It is noted that the maximum values did not appear at the same levels for different charge distances.

The accelerometer mounted on the structure (Figs 10 and 11) enabled one to investigate the structural acceleration with respect to the charge mass, distance to the front of silo and the installed charge depth. The tests have provided evidence that the increase of structure acceleration was related to the increase of charge mass and depth. Figure 29 shows the structural acceleration-time histories for the charge masses of $0.6 \mathrm{~kg}$ and $1.2 \mathrm{~kg}$. Figures 30 and 31 show that the acceleration magnitude depended on the distance and Fig. 32 shows that the acceleration magnitude depended on the charge depth.

The peak acceleration is comparatively large for charge explosions at a distance of $2.0 \mathrm{~m}$. However, the peak acceleration abruptly decreased at a distance $3.7 \mathrm{~m}$ (Fig. 31), which is nearly proportional to the change of the charge-to-structure distance.

From Fig. 32 it can be seen that comparatively shallow charge depths (i.e. 1.5-1.8 m) caused smaller accelerations in the buried cylindrical structure than by larger charge depth. 


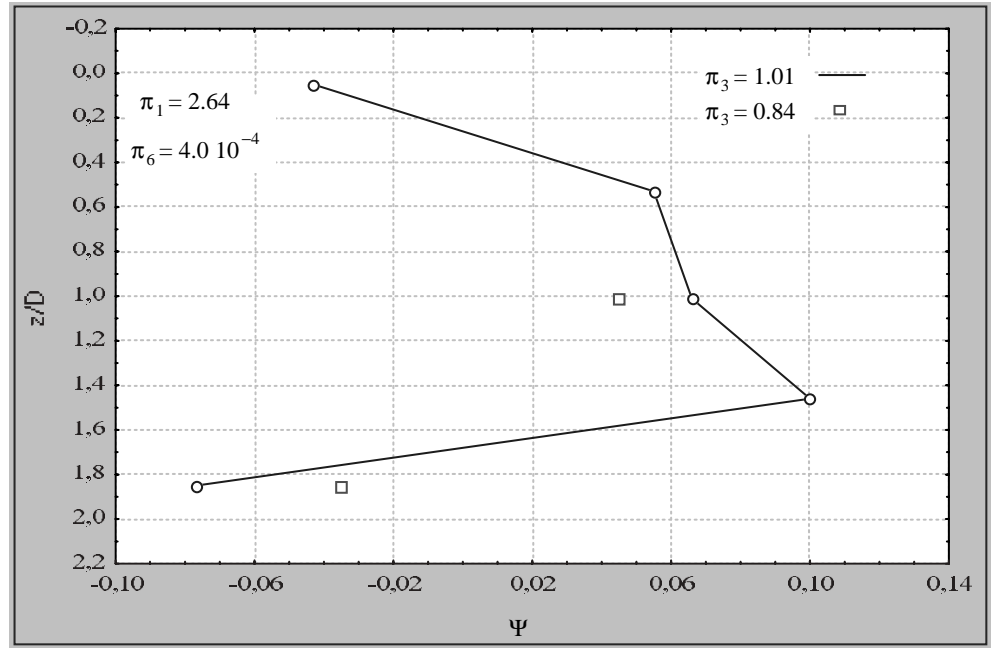

Fig. 28. Influence of charge depth parameter $\pi_{3}$ on value of tangential pressure coefficient $\Psi$.

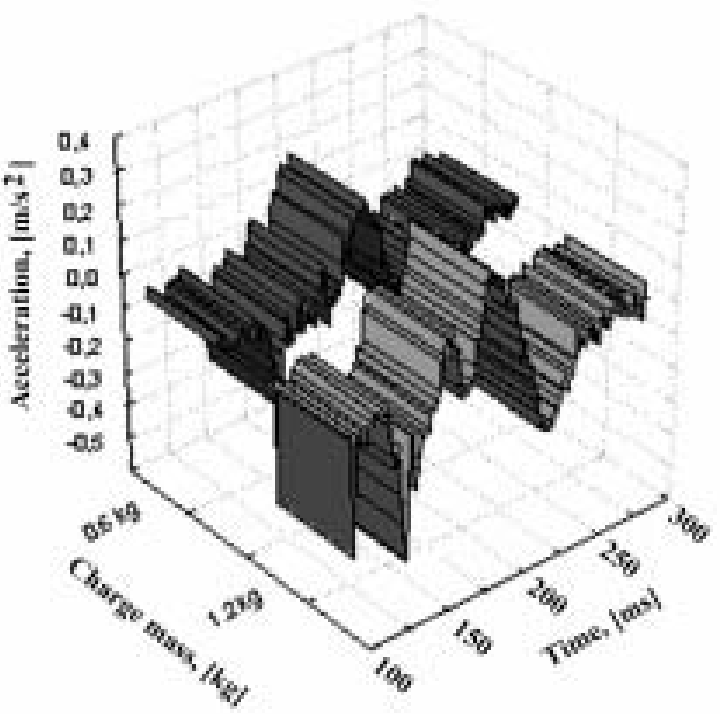

Fig. 29. Acceleration histories of the silo structure vs. the charge mass.

\section{Comparison semi-empirical approach}

Free-field stresses generated by the detonation of buried conventional weapon can be estimated with semi-empirical Eq. (3) from [6], or Fig. 33, as follows.

$$
P_{0}=\beta f(\rho c)\left(\frac{R}{W^{1 / 3}}\right)^{-n}
$$

where

$P_{0}$ - peak amplitude of the stress wave at the time of arrival,

$f$ - coupling factor of the explosive energy,

$\rho c$ - acoustic impedance of soil,

$n$ - attenuation coefficient, 


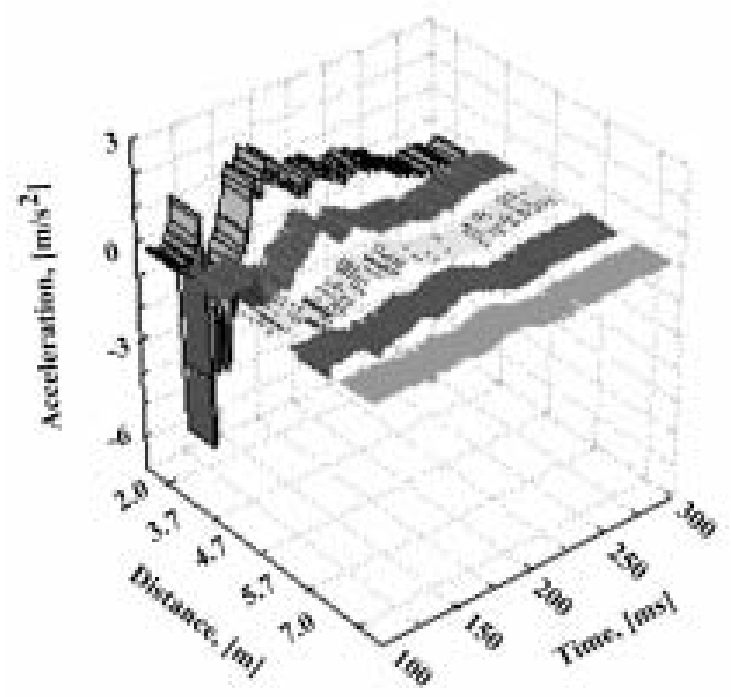

Fig. 30. Acceleration histories of silo structure depend on distance charge mass-front of structure for charge mass of $1.2 \mathrm{~kg}$.

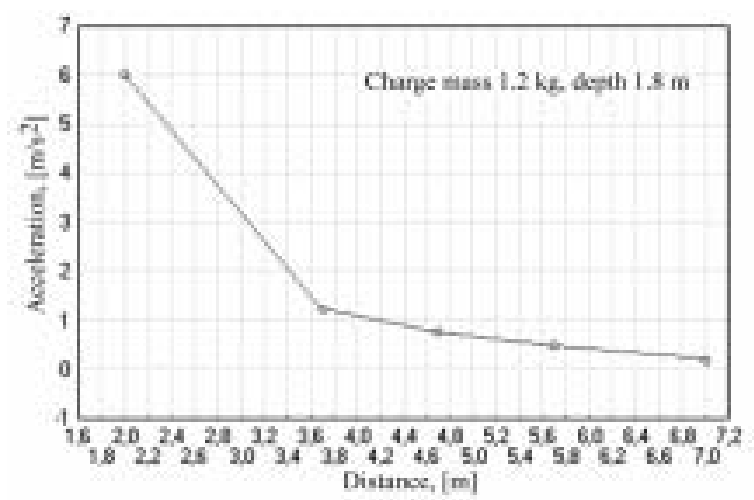

Fig. 31. Influence of charge distance from structure on structure acceleration for the $1.2 \mathrm{~kg}$ charge.

$W$ - TNT equivalent charge weight,

$R$ - distance measured from the c.g. of the weapon;

and

$\beta=160$ for $P_{0}$ in psi, $\rho c$ in $\mathrm{psi} / \mathrm{fps}, W$ in $\mathrm{lbs}$, and $R$ in $\mathrm{ft}$;

or

$\beta=0.47$ for $P_{0}$ in $\mathrm{MPa}, \rho c$ in $\mathrm{MPa}-\mathrm{s} / \mathrm{m}, W$ in Newtons, $R$ in meters, and $n=2.75$.

For example, the scaled distance $R / W^{1 / 3}$ in units of $\mathrm{ft} / \mathrm{lb}^{1 / 3}$ is derived for the following case:

$W=1.2 \mathrm{~kg}=2.64 \mathrm{lbs}$, and $R=2.0 \mathrm{~m}=6.56 \mathrm{ft}$

Hence, it $R / W^{1 / 3}=4.75 \mathrm{ft} / \mathrm{lb}^{1 / 3}$

From Fig. 33, for this value of $R / W^{1 / 3}$ the stress for dry loose sand is:

$P_{0}=\sim 11 \mathrm{psi}$, or $11 \times 6.895=75.55 \mathrm{kPa}$.

This stress value is higher than the maximal measured pressure value of $48 \mathrm{kPa}$ (Fig. 18 ). This difference might indicate that some explosive energy was dissipated by venting into the atmosphere, and/or other dissipation phenomena. However, since the charge depth was $1.8 \mathrm{~m}$, its scaled depth was $1.8 / 1.2^{1 / 3}=1.69 \mathrm{~m} / \mathrm{kg}^{1 / 3}$, or $5.9 / 2.64^{1 / 3}=4.27 \mathrm{ft} / \mathrm{lb}^{1 / 3}$, one would expect that full coupling should exist for these conditions, as indicated in [6], or in Table 2. 


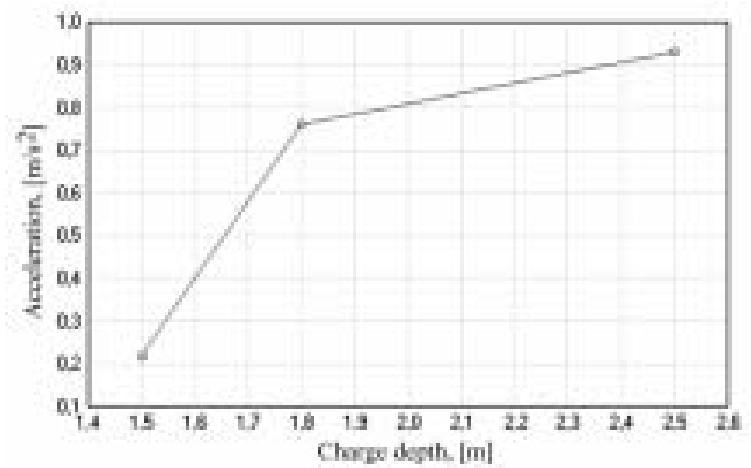

Fig. 32. Influence of charge depth installation on structure acceleration $(W=1.2 \mathrm{~kg}, R=4.7 \mathrm{~m})$.

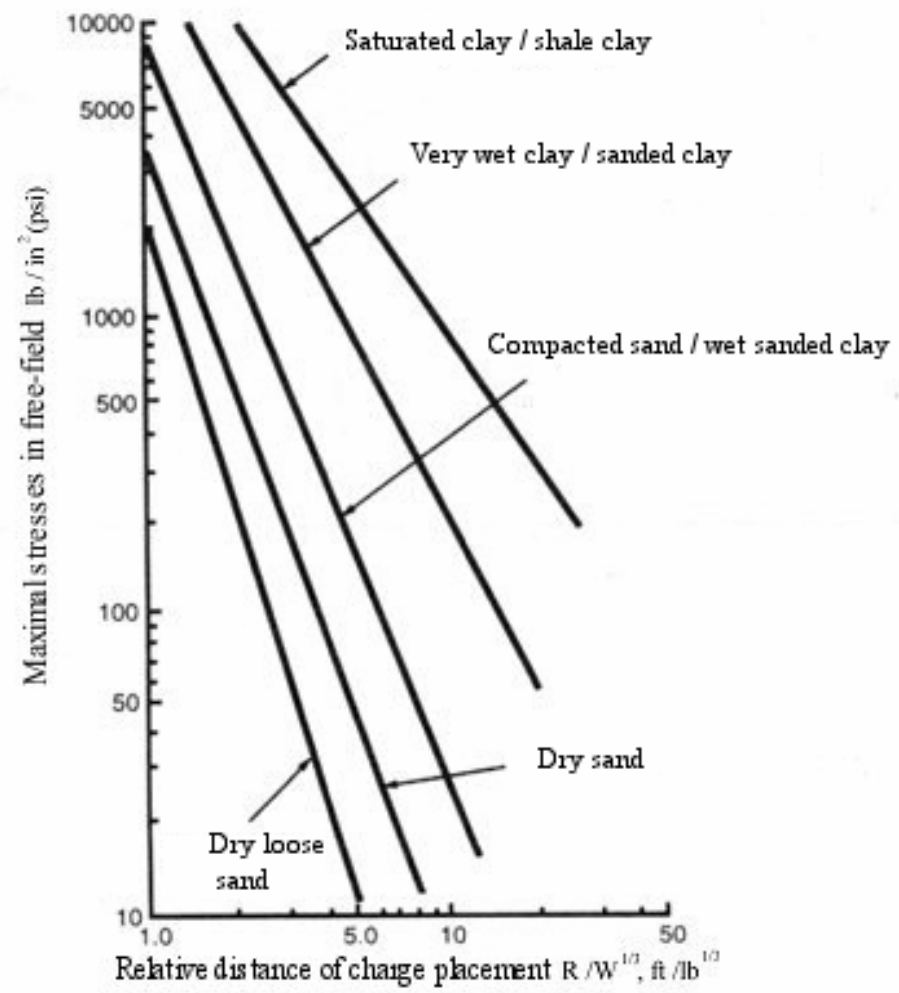

Fig. 33. Maximal stresses in the soil caused by underground explosion for different soil types (according Drake and Little [5], see Bulson [1]).

\section{Conclusions}

The following conclusions were drawn from this paper:

1. The maximum absolute increase in normal pressure caused by a buried explosion acted primarily on the structure bottom, regardless of the charge weight.

2. The highest, relative dynamic pressure increase of $470 \%$, as compared with static pressure calculated according to Coulomb's equation, was recorded in the upper part of the structure. This finding should be taken into account when designing the upper part of buried protective structures. 
3. The value of the maximum-recorded normal pressure appears first at the bottom of the structure and, as time progressed, the peak pressure location moved upward and attained the maximum pressure value at the upper part of the silo.

4. The maximum tangential pressure did not coincide with the explosion wave at early time when it reached the structure front, but it did only at a later time.

5. The maximum value of the normal pressure at a large distance from the explosion did not occur on the front surface, but on the sides of the structure.

6. The greatest value of the tangential pressure caused by the shock wave did not appear on the front surface, but at the rear of the structure.

\section{Acknowledgements}

The research described in this paper has been conducted in the College of Military Engineering, Wroclaw and was jointly supported by CME and a Grant from Scientific Research Committee, Warsaw No. 7 T07E 04910. This support is gratefully acknowledged. The authors would like to thank Adam Walczak, College of Military Engineering, Wroclaw, for his cooperation in providing some of the experimental data used in this research.

\section{References}

[1] P.S. Bulson, Explosive Loadings of Engineering Structures Edition SPON, London, 1997.

[2] R., Butterfield, Dimensional analysis for geotechnical engineers, Geotechnique 49(3) (1999), 357-366.

[3] H.L. Chen, S.P. Shah and L.M. Keer, Dynamic response of shallow-buried cylindrical structures, Journal of Engineering Mechanics 116(1) (January, 1990).

[4] A.N. Dancygier and Y.S. Karinski, The model to assess the effect of soil shear resistance on the response of soil-buried structures under dynamic loads, Engineering Structures 21 (1999), 1055-1065.

[5] J.L. Drake and C.D. Little, Ground shock from penetrating conventional weapons, Proc. Symposium on Interaction of Non-nuclear Munitions with Structures, Colorado, USA, 1983.

[6] Fundamentals of protective design for conventional weapons, TM5-855-1, US Army Engineer Waterways Experiment Station, Vicksburg, Miss., July, 1984.

[7] T. Ganev, F. Yamazaki and T. Katayama, Observation and numerical analysis of soil-structure interaction of a reinforced concrete tower, Earthquake Engineering and Structural Dynamics 24 (1995), 431-503.

[8] D. Hampton and W.B. Truesdale, Stress and strain gages for use in soil dynamic research, Instrument Society of America, 22nd Annual ISA Conference and Exhibit, Chicago, Illinois, September 11-14, 1967.

[9] V.E. Karamzin and V.N. Klemeshev, Evaluation of reliability of soil dynamic stress measurement using type PDP transducers, Translated from Osnovaniya, Fundamenty i Mekhanika Gruntov, No. 1, Plenum Publishing Corporation, January-February, 1985 , pp. 16-17.

[10] S. Kobielak, A. Walczak, M. Bogdański, L. Grabowski and M. Mikołajewski, Dynamic soil pressure on underground fortification structures caused by explosion actions, Report of College of Military Engineering, Part I, Wrocław, 1996, in Polish.

[11] S. Kobielak, A. Walczak, M Bogdański and J. Szelka, Dynamic soil pressure on underground fortification structures caused by explosion actions, Report of College of Military Engineering, Part II, Wrocław, 1997, in Polish.

[12] S. Kobielak, A. Walczak, M. Bogdański and J. Szelka, Dynamic soil pressure on underground fortification structures caused by explosion actions, Report of College of Military Engineering, Part III, Wrocław, 1998, in Polish.

[13] T. Krauthammer, Shallow-buried RC box-type structures of shallow-buried cylindrical structures, Journal of Engineering Mechanics 116(1) (January 1990).

[14] T. Krauthammer, Modern Protective Structures, Design, Analysis and Evaluation, Course notes, The Pennsylvania State University, 2003, 2000.

[15] T. Krauthammer, S. Shahriar and H.M. Shannaa, Response of reinforced concrete elements to severe impulsive loads, Journal of Structural Engineering 116(4) (April, 1990), 1061-1070.

[16] C.W. Lampson, Effects of impact and explosions, Explosions in Earth, NRDC Washington, USA, Vol. 1, Chapter 3, 1946.

[17] R. Luna and H. Jadi, Determination of dynamic soil properties using geophysical methods, Proceedings of the First International Conference on the Application of Geophysical and NDT Methodologies to Transportation Facilities and Infrastructure, St. Louis, MO, December 2000.

[18] J. Novosad and J. Šmid, Contribution to the measurement of normal and shear stresses in walls of bunkers, Collection Czechoslav. Chem. Commun. 37 (1972).

[19] Proceedings Transient loading and response of structures, in: Int. Symposium Honoring Mr. Arnfinn Jenssen, M. Langseth and T. Krauthammer, eds, Trondheim, Norway, May 25-27, 1998.

[20] D.C. Sachs and L.M. Swift, Small explosion tests, Project MOLE, US Air Force Special Weapon Center Contract 291, Stanford Research Institute, Stanford, California, December 1955.

[21] G.E. Triandafilidis, Soil-stress gage design and evaluation, Journal of Testing and Evaluation 2(3) (1974). 
[22] A.S. Veletsos and A.H. Younan, Dynamic soil pressures on rigid cylindrical vaults, Earthquake Engineering and Structural Dynamics 23(1994), 645-669.

[23] P. Weidlinger and E. Hinman, Analysis of underground protective structures, Journal of Structural Engineering, Div., ASCE 114(7) (1988), $1658-1672$.

[24] A. Weiler and F.H. Kulhawy, Behavior of stress cells in soil, Contract, Report B-49 (4), School of Civil and Environmental Engineering Cornell University Ithaca, New York, October 1978.

[25] P.S. Westine and G.J. Friesenhahn, Free-field ground shock pressures from buried detonations in saturated and unsaturated soil, Proc. Symposium on Interaction of Non-nuclear Munitions with Structures, Colorado, USA, 1983. 

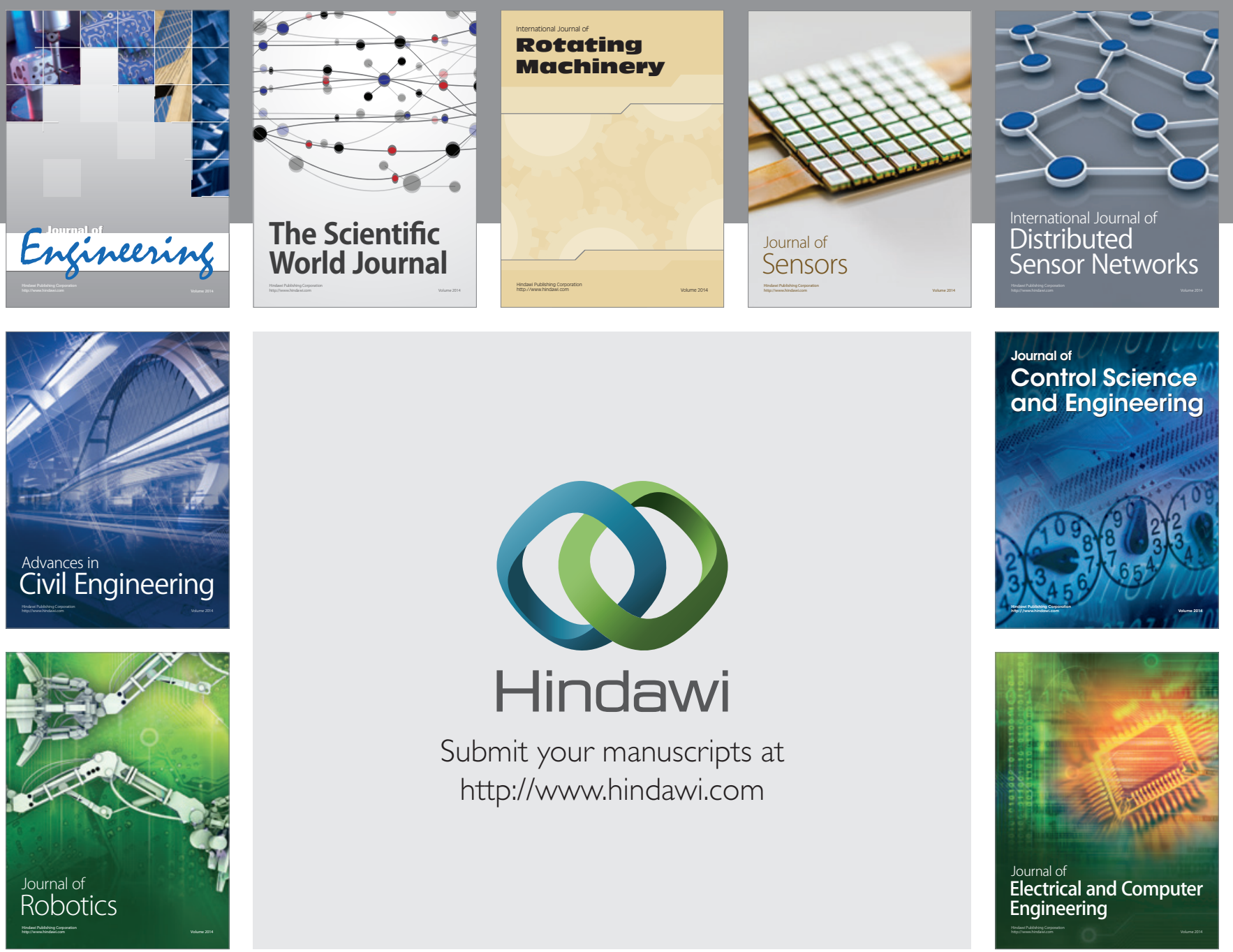

Submit your manuscripts at

http://www.hindawi.com
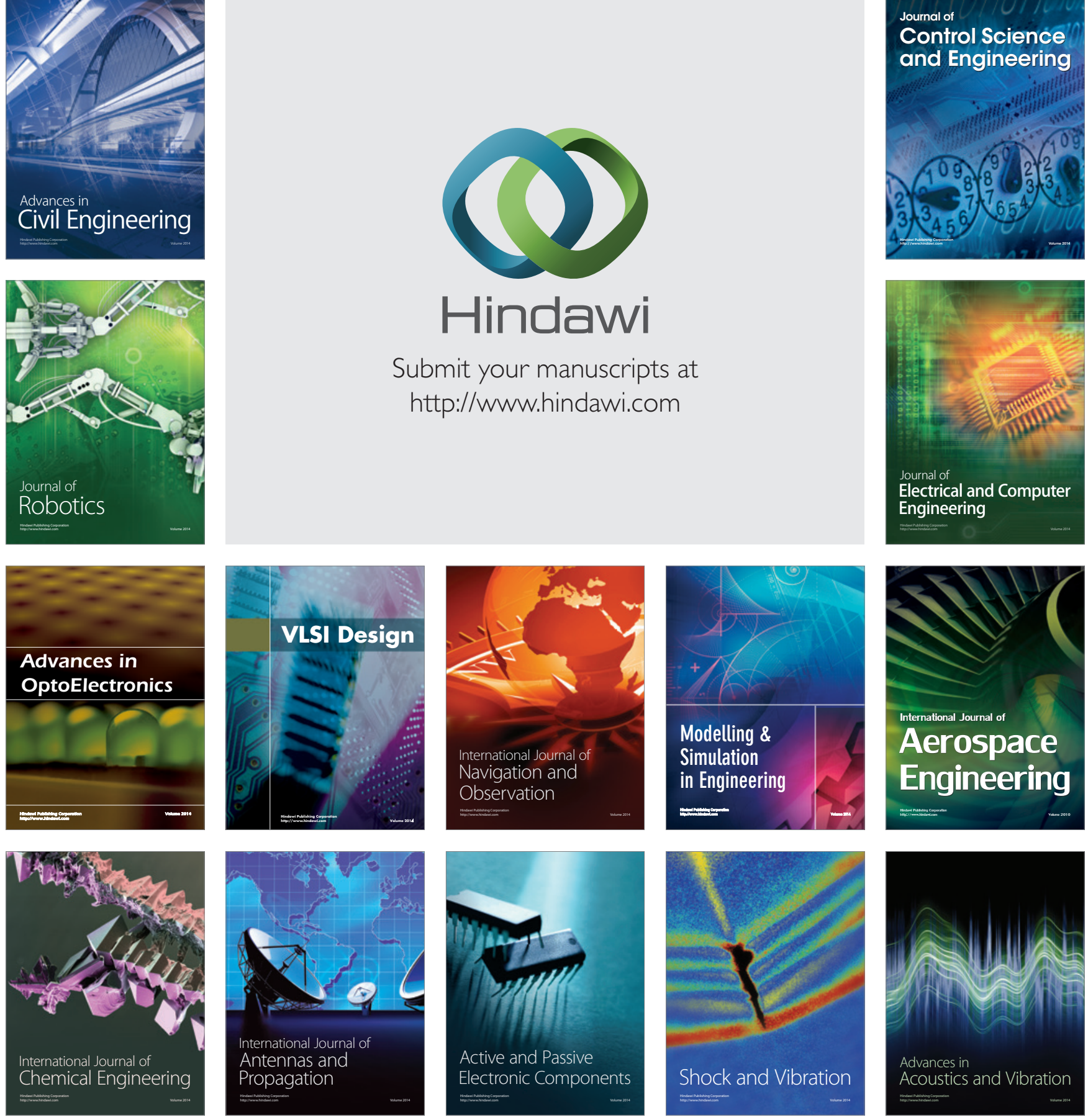